Article

\title{
New Diterpenes with a Fused 6-5-6-6 Ring System Isolated from the Marine Sponge-Derived Fungus Trichoderma harzianum
}

\author{
Takeshi Yamada *(D), Ayano Fujii and Takashi Kikuchi ${ }^{(0)}$ \\ Department of Medicinal Molecular Chemistry, Osaka University of Pharmaceutical Sciences, 4-20-1, Nasahara, \\ Takatsuki, Osaka 569-1094, Japan \\ * Correspondence: yamada@gly.oups.ac.jp; Tel./Fax: +81-726-901-085
}

Received: 5 July 2019; Accepted: 15 August 2019; Published: 19 August 2019

\begin{abstract}
New diterpenes, namely, trichodermanins F-H, with a fused 6-5-6-6 ring system were isolated from the fungus Trichoderma harzianum OUPS-111D-4 separated from a marine sponge Halichondria okadai. These chemical structures were elucidated by 1D and 2D NMR as well as high-resolution fast atom bombardment mass spectrometry (HRFABMS) spectral analyses. We established their absolute stereostructures by application of the modified Mosher's method or circular dichroism (CD) spectroscopy. In addition, their cytotoxicities were assessed using several cancer cell lines, with $\mathbf{1}$ and $\mathbf{2}$ exhibiting modest activities.
\end{abstract}

Keywords: diterpenes; trichodermanins; Trichoderma harzianum; Halichondria okadai; fused 6-5-6-6 ring system; cytotoxicity

\section{Introduction}

A number of secondary metabolites derived from marine microorganisms have diverse structures and exhibit unexpected biological activities [1-4]. This motivated us to target marine microorganisms as a source of seed compounds for antitumor chemotherapy agents, and we have reported many cytotoxic metabolites to date [5-8]. As part of this ongoing study, we examined the metabolites of the fungus Trichoderma harzianum separated from a piece of the marine sponge Halichondria okadai. We have already reported the isolation, structural determination, and cytotoxicity of the decalin derivatives tandyukisins A-F derived from this fungus [9-11] as well as those of trichodermanins C, D, and E (1), classified as diterpenes with a rare fused 6-5-6-6 ring system [12]. In the continuing search for cytotoxic metabolites from this fungal strain, we isolated three new compounds, namely, trichodermanins F-H (2-4). Except for our study, there are only two other reports of natural products consisting of this ring system, i.e., trichodermanin A [13] and wickerols A and B [14]. We have previously reported the first determination of the absolute configurations of trichodermanins $C$ and $D$ by application of the modified Mosher's method [15]. In the present study, we established the absolute configuration of trichodermanin E (1), which was confirmed by circular dichroism (CD) spectroscopy. In addition, we also examined the absolute stereostructures of the newly isolated trichodermanins $\mathrm{F}-\mathrm{H}(2-4)$. We herein describe the evaluation of the cytotoxic activities of $\mathbf{1 - 4}$, although they exhibited zero or weak activities.

\section{Results and Discussion}

T. harzianum, a fungus from $\mathrm{H}$. okadai, was cultured at $27^{\circ} \mathrm{C}$ for six weeks in a medium $(70 \mathrm{~L})$ containing $1 \%$ glucose, $1 \%$ malt extract, and $0.05 \%$ peptone in artificial seawater adjusted to $\mathrm{pH} 7.5$. After incubation, the EtOAc extract of the culture filtrate was purified via cytotoxic assay-directed 
fractionation using a stepwise combination of silica gel column and Sephadex LH-20 chromatography, followed by reverse-phase HPLC, affording trichodermanins E (1) $(0.93 \mathrm{mg}, 0.011 \%), \mathrm{F}$ (2) (3.7 mg, $0.043 \%), \mathrm{G}(3)(4.6 \mathrm{mg}, 0.053 \%)$, and H (4) (1.3 mg, 0.015\%)

The molecular formula of trichodermanin E (1) was established as $\mathrm{C}_{20} \mathrm{H}_{34} \mathrm{O}_{3}$ based on the molecular ion $\mathrm{m} / \mathrm{z} 345.2397[\mathrm{M}+\mathrm{Na}]^{+}$in high-resolution fast atom bombardment mass spectrometry (HRFABMS) (Figure S7). Absorption in the IR spectrum at $3383 \mathrm{~cm}^{-1}$ indicated the presence of hydroxy groups. The relative stereostructure of $\mathbf{1}$ has previously been reported using distortionless enhancement by polarization transfer (DEPT), heteronuclear multiple quantum coherence spectroscopy (HMQC), and NOESY experiments with the ${ }^{1} \mathrm{H}$ and ${ }^{13} \mathrm{C}$ NMR spectra of 1 (Figure 1, and Figures S1-S6, Table 1, and Table S1) [12]. However, the assignment of its absolute configuration was not performed. In the present study, the absolute stereostructure of $\mathbf{1}$ was elucidated by acylation with $p$-bromobenzoyl chloride to apply the dibenzoate rule [16]. In the CD spectrum of the dibenzoate 1a, the negative Cotton effect $\left(\Delta \varepsilon_{258}-15\right)$ demonstrated that the screw sense of two benzoate chromophores at $C-1$ and $\mathrm{C}-2$ was counterclockwise. Therefore, the absolute configurations for C-1 and C-2 were revealed as $R$ and $R$, respectively (Figure 2) [16].

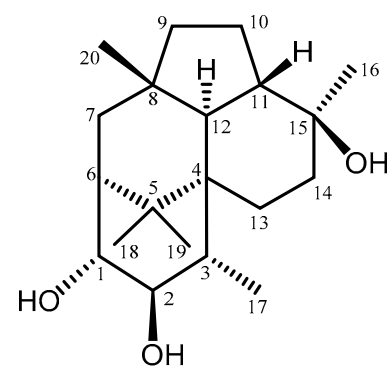

1

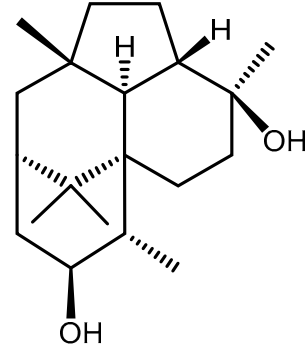

2

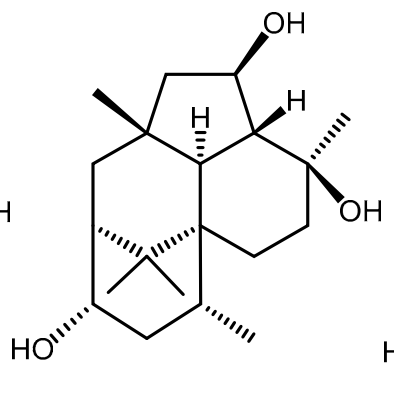

3

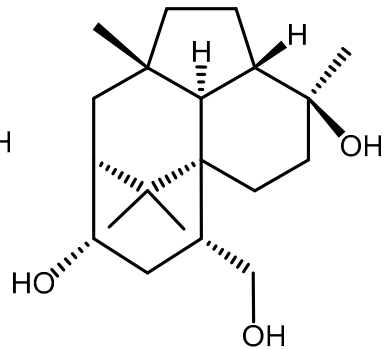

4

Figure 1. Structures of trichodermanins E-H (1-4).

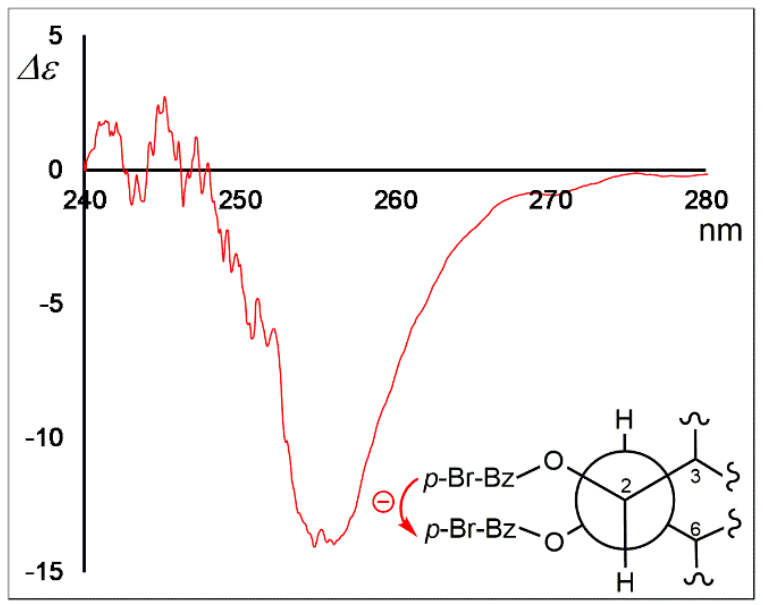

Figure 2. Circular dichroism (CD) spectrum of the dibenzoate of trichodermanin E (1a). 
Table 1. NMR spectral data for 1-4 in $\mathrm{CDCl}_{3}$.

\begin{tabular}{|c|c|c|c|c|c|c|c|c|c|c|c|c|c|c|c|c|}
\hline \multirow{3}{*}{$\begin{array}{c}\text { Position } \\
1 \alpha\end{array}$} & \multicolumn{4}{|c|}{1} & \multicolumn{4}{|c|}{2} & \multicolumn{4}{|c|}{3} & \multicolumn{4}{|c|}{4} \\
\hline & \multicolumn{2}{|c|}{$\delta_{\mathrm{H}}{ }^{a}$} & \multicolumn{2}{|c|}{$\delta_{\mathrm{C}}$} & \multicolumn{2}{|c|}{$\delta_{\mathrm{H}}^{a}$} & \multicolumn{2}{|c|}{$\delta_{\mathrm{C}}$} & \multicolumn{2}{|c|}{$\delta_{\mathrm{H}}^{a}$} & \multicolumn{2}{|c|}{$\delta_{\mathrm{C}}$} & \multicolumn{2}{|c|}{$\delta_{\mathrm{H}}{ }^{a}$} & \multicolumn{2}{|c|}{$\delta_{\mathrm{C}}$} \\
\hline & & & & & 2.54 & ddd & 36.5 & $(\mathrm{t})$ & & & & & & & & \\
\hline $1 \beta$ & 4.11 & $\mathrm{~d}$ & 80.4 & (d) & 1.68 & $\mathrm{~m}$ & & & 4.20 & $\mathrm{dd}$ & 72.6 & (d) & 4.24 & $\mathrm{dd}$ & 72.1 & (d) \\
\hline $2 \alpha$ & 3.88 & $\mathrm{dd}$ & 83.7 & (d) & 4.30 & ddd & 74.2 & (d) & 2.66 & ddd & 41.8 & $(t)$ & 2.74 & ddd & 36.9 & $(\mathrm{t})$ \\
\hline $2 \beta$ & & & & & & & & & 1.45 & $\mathrm{~m}$ & & & 1.64 & ddd & & \\
\hline 3 & 1.88 & qd & 36.6 & (d) & 1.98 & $\mathrm{qd}$ & 37.9 & (d) & 2.10 & $\mathrm{~m}$ & 26.7 & (d) & 1.88 & dddd & 34.0 & (d) \\
\hline 4 & & & 41.2 & (s) & & & 40.8 & (s) & & & 38.9 & (s) & & & 38.9 & (s) \\
\hline 5 & & & 39.4 & (s) & & & 39.0 & (s) & & & 39.0 & (s) & & & 38.5 & (s) \\
\hline 6 & 1.50 & $\mathrm{dd}$ & 53.2 & (d) & 1.62 & $\mathrm{~m}$ & 41.8 & (d) & 1.41 & $\mathrm{dd}$ & 52.2 & (d) & 1.45 & $\mathrm{dd}$ & 52.2 & (d) \\
\hline $7 \alpha$ & 1.78 & $\mathrm{dd}$ & 40.9 & $(\mathrm{t})$ & 1.71 & $\mathrm{dd}$ & 42.5 & $(\mathrm{t})$ & 1.69 & $\mathrm{dd}$ & 41.3 & $(\mathrm{t})$ & 1.74 & $\mathrm{dd}$ & 40.9 & $(\mathrm{t})$ \\
\hline $7 \beta$ & 1.70 & $\mathrm{dd}$ & & & 1.56 & $\mathrm{dd}$ & & & 1.65 & $\mathrm{dd}$ & & & 1.68 & $\mathrm{dd}$ & & \\
\hline 8 & & & 39.6 & (s) & & & 39.7 & (s) & & & 38.8 & (s) & & & 39.2 & (s) \\
\hline $9 \alpha$ & 1.03 & $\mathrm{~m}$ & 43.5 & $(\mathrm{t})$ & 1.02 & $\mathrm{~m}$ & 43.9 & $(\mathrm{t})$ & 1.48 & $\mathrm{~m}$ & 52.2 & $(t)$ & 1.03 & $\mathrm{~m}$ & 43.5 & $(\mathrm{t})$ \\
\hline $9 \beta$ & 1.43 & $\mathrm{~m}$ & & & 1.43 & $\mathrm{~m}$ & & & & & & & 1.43 & $\mathrm{~m}$ & & \\
\hline $10 \alpha$ & 1.59 & $\mathrm{~m}$ & 21.6 & $(\mathrm{t})$ & 1.60 & $\mathrm{~m}$ & 21.6 & $(\mathrm{t})$ & 4.38 & ddd & 72.9 & (d) & 1.59 & $\mathrm{~m}$ & 21.5 & $(\mathrm{t})$ \\
\hline $10 \beta$ & 1.80 & $\mathrm{~m}$ & & & 1.81 & $\mathrm{~m}$ & & & & & & & 1.80 & $\mathrm{~m}$ & & \\
\hline 11 & 1.81 & $\mathrm{dd}$ & 44.2 & (d) & 1.85 & $\mathrm{~m}$ & 44.4 & (d) & 1.85 & $\mathrm{dd}$ & 55.0 & (d) & 1.88 & ddd & 44.1 & (d) \\
\hline 12 & 1.32 & d & 51.8 & (d) & 1.30 & $\mathrm{~d}$ & 51.9 & (d) & 1.28 & d & 50.6 & (d) & 1.28 & $\mathrm{~d}$ & 52.0 & (d) \\
\hline $13 \alpha$ & 1.23 & ddd & 26.3 & $(\mathrm{t})$ & 1.18 & ddd & 26.4 & $(\mathrm{t})$ & 1.19 & ddd & 25.9 & $(t)$ & 1.28 & $\mathrm{~m}$ & 25.5 & $(\mathrm{t})$ \\
\hline $13 \beta$ & 1.72 & ddd & & & 1.68 & $\mathrm{~m}$ & & & 1.74 & ddd & & & 1.52 & $\mathrm{~m}$ & & \\
\hline $14 \alpha$ & 1.64 & ddd & 41.1 & $(\mathrm{t})$ & 1.62 & $\mathrm{~m}$ & 41.2 & $(\mathrm{t})$ & 1.60 & ddd & 41.0 & $(t)$ & 1.67 & $\mathrm{~m}$ & 40.87 & $(\mathrm{t})$ \\
\hline $14 \beta$ & 1.46 & ddd & & & 1.46 & ddd & & & 1.50 & ddd & & & 1.50 & $\mathrm{~m}$ & & \\
\hline 15 & & & 73.6 & (s) & & & 73.8 & (s) & & & 73.1 & (s) & & & 73.6 & (s) \\
\hline 16 & 1.18 & $\mathrm{~s}$ & 20.5 & (q) & 1.18 & $\mathrm{~s}$ & 20.4 & (q) & 1.22 & $\mathrm{~s}$ & 21.5 & (q) & 1.18 & $\mathrm{~s}$ & 20.5 & (q) \\
\hline \multirow[t]{2}{*}{17} & 1.23 & $\mathrm{~d}$ & 20.0 & (q) & 1.19 & $\mathrm{~d}$ & 20.4 & (q) & 1.09 & d & 22.4 & (q) & 3.60 & $\mathrm{dd}$ & 68.1 & $(\mathrm{t})$ \\
\hline & & & & & & & & & & & & & 3.95 & $\mathrm{dd}$ & & \\
\hline $18 a x$ & 0.99 & $\mathrm{~s}$ & 25.7 & (q) & 0.95 & $\mathrm{~s}$ & 25.3 & (q) & 0.97 & $\mathrm{~s}$ & 25.8 & (q) & 0.99 & $\mathrm{~s}$ & 25.7 & (q) \\
\hline $19 \mathrm{eq}$ & 1.04 & $\mathrm{~s}$ & 25.2 & (q) & 0.96 & $\mathrm{~s}$ & 25.4 & (q) & 1.14 & $\mathrm{~s}$ & 24.9 & (q) & 1.13 & $\mathrm{~s}$ & 25.5 & (q) \\
\hline 20 & 0.98 & $\mathrm{~s}$ & 19.8 & (q) & 1.13 & $\mathrm{~s}$ & 20.3 & (q) & 1.17 & $\mathrm{~s}$ & 21.4 & (q) & 0.92 & $\mathrm{~s}$ & 19.5 & (q) \\
\hline
\end{tabular}

Trichodermanin $\mathrm{F}(2)$ was assigned the formula $\mathrm{C}_{20} \mathrm{H}_{34} \mathrm{O}_{2}$ by HRFABMS $m / z 289.2534[\mathrm{M}-\mathrm{Na}]^{+}$ (calcd for $\mathrm{C}_{20} \mathrm{H}_{34} \mathrm{O}_{3} \mathrm{Na}$ : 289.2532), which contained one less oxygen atom than that of $\mathbf{1}$ (Figure S14). Consideration of the ${ }^{1} \mathrm{H}$ and ${ }^{13} \mathrm{C}$ NMR spectra of 2 (Table 1 and Table S2, and Figures S8, S9 and S12), including 2D NMR spectra, suggested that compound 2 had one secondary methyl (C-17); four tertiary methyls (C-16, C-18, C-19, and C-20); six sp ${ }^{3}$-hybridized methylenes (C-1, C-7, C-9, C-10, C-13, and C-14); five $\mathrm{sp}^{3}$ methines (C-2, C-3, C-6, C-11, and C-12), including one oxygen-bearing sp ${ }^{3}$ methine (C-2); and four quaternary $\mathrm{sp}^{3}$ carbons (C-4, C-5, C-8, and C-15), including one oxygen-bearing quaternary $\mathrm{sp}^{3}$ carbon (C-15). ${ }^{1} \mathrm{H}-{ }^{1} \mathrm{H}$ correlation spectroscopy (COSY) revealed three partial structures (Figure 3 and Figure S10). In the HMBC spectrum (Figure 3 and Figure S13), the correlation from 15-methyl to $\mathrm{C}-11, \mathrm{C} 14$, and C-15; from 8-methyl to C-7, C-8, C-9, and C-12; from germinal dimethyl (H-18 and $\mathrm{H}-19)$ to $\mathrm{C}-4, \mathrm{C}-5$, and $\mathrm{C}-6$; from $\mathrm{H}-12$ to $\mathrm{C}-3, \mathrm{C}-4$, and $\mathrm{C}-5$; and from $\mathrm{H}-13$ to $\mathrm{C}-12$ showed three cyclohexane rings and a cyclopentane comprising a fused 6-5-6-6 ring system to give the planar structure of 2 , as shown in Figure 3. 


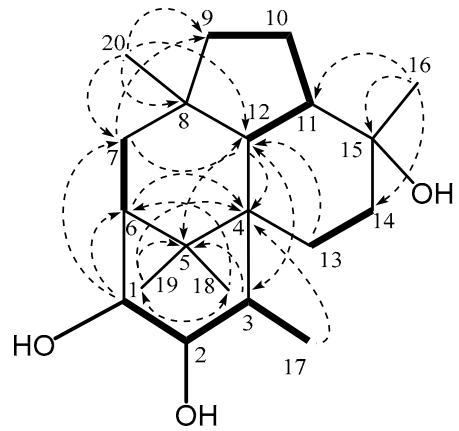

1

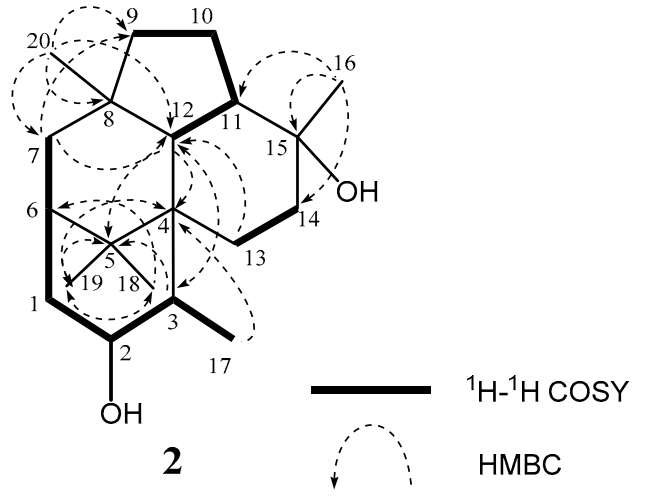

Figure 3. Key ${ }^{1} \mathrm{H}-{ }^{1} \mathrm{H}$ COSY and HMBC correlations for $(\mathbf{1}, \mathbf{2})$.

For the stereochemistry of $\mathbf{2}$, the relative configuration and conformation were investigated by NOESY experiments (Table S2 and Figure 4 and Figure S11). In the NOESY analysis of 2, correlations from $\mathrm{H}-2 \alpha$ to $\mathrm{H}-19$; from $\mathrm{H}-3$ to $\mathrm{H}-11, \mathrm{H}-14 \beta$, and $\mathrm{H}-20$; and from $\mathrm{H}-1 \beta$ to $\mathrm{H}-20$ indicated that cyclohexane ring A existed in the boat conformation with $3-\mathrm{CH}_{3}$ in the $\alpha$-orientation. In cyclohexane ring $B$, the above correlations and the NOESY cross peaks $(\mathrm{H}-7 \alpha / \mathrm{H}-12$ and $\mathrm{H}-18)$ demonstrated that ring $\mathrm{B}$ existed in the chair conformation and that $5-\mathrm{CH}_{3}(\mathrm{C}-18), \mathrm{H}-7 \alpha$, and $\mathrm{H}-12$ were oriented in coaxial arrangements. The NOESY correlations between $\mathrm{H}-3, \mathrm{H}-11$, and $\mathrm{H}-14 \beta$ indicated that cyclohexane ring $\mathrm{C}$ also existed in the chair conformation. In addition, the correlations $(\mathrm{H}-18 / \mathrm{H}-13 \alpha, \mathrm{H}-11 / \mathrm{H}-20$, $\mathrm{H}-14 \alpha / \mathrm{H}-16$, and $\mathrm{H}-12 / \mathrm{H}-16)$ revealed that $\mathrm{H}-11, \mathrm{H}-13 \alpha, \mathrm{H}-14 \beta$, and $15-\mathrm{CH}_{3}(\mathrm{C}-16)$ were oriented in coaxial arrangements and that the ring juncture between cyclohexane rings $\mathrm{B}$ and $\mathrm{C}$ was trans (Figure 4 and Figure S11, and Table S2).

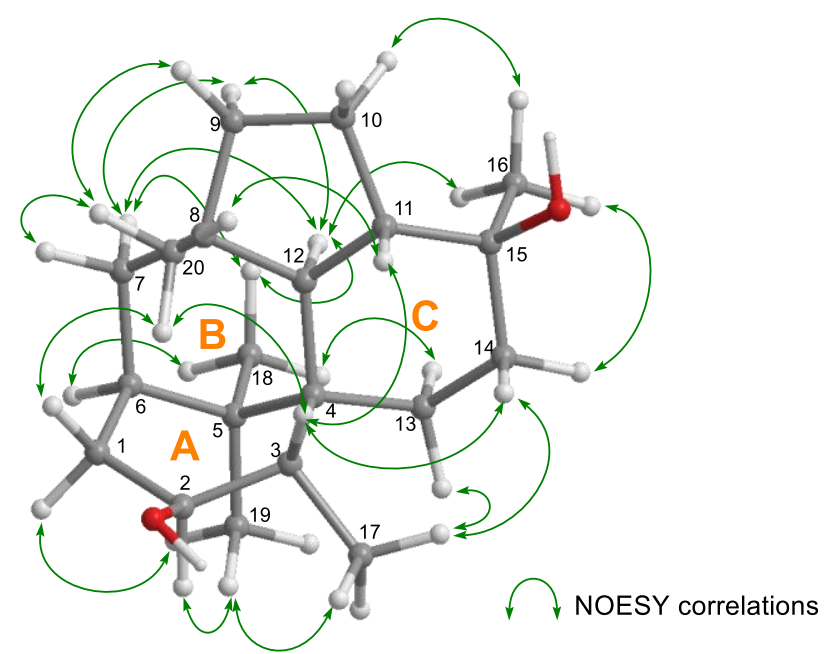

2

Figure 4. Key NOESY correlations for 2.

A difference in the structural features of $\mathbf{2}$ and $\mathbf{1}$ was the absence of a secondary hydroxyl group at C-1. Therefore, we applied the modified Mosher's method [15] to determine their absolute stereostructures. The ${ }^{1} \mathrm{H}$ chemical shift differences between the $(S)$ - and (R)-MTPA esters $\mathbf{2 a}$ and $\mathbf{2 b}$ showed positive on the right side and negative on the left side of the MTPA plane; therefore, we revealed an $S$ configuration at C-2 (Figure 5 and Table S5). 


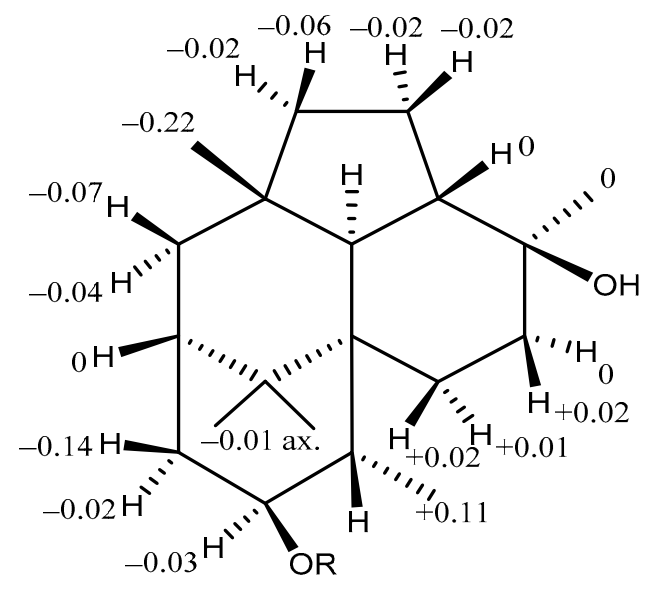

$$
\begin{aligned}
& \text { 2a } \mathrm{R}=(S) \text {-MTPA ester } \\
& \text { 2b } \mathrm{R}=(R)-\text { MTPA ester }
\end{aligned}
$$

Figure $5 .{ }^{1} \mathrm{H}$ chemical-shift differences between the (S)- and (R)-MTPA esters $\mathbf{2 a}$ and $\mathbf{2 b}$.

Trichodermanin $\mathrm{G}$ (3) was assigned the formula $\mathrm{C}_{20} \mathrm{H}_{34} \mathrm{O}_{3}$ by HRFABMS $m / z 345.2395[\mathrm{M}+\mathrm{Na}]^{+}$ (calcd for $\mathrm{C}_{20} \mathrm{H}_{34} \mathrm{O}_{3} \mathrm{Na}$ : 345.2396), which was the same as that of $\mathbf{1}$ (Figure S21). The NMR spectral features (Table 1 and Table S3, and Figures S15, S16 and S19) resembled those of 1, except for the proton signals for $\mathrm{H}-2\left(\delta_{\mathrm{H}} 1.45, \mathrm{~m}\right.$ and $\left.\delta_{\mathrm{H}} 2.66, \mathrm{ddd}\right), \mathrm{H}-3\left(\delta_{\mathrm{H}} 2.10, \mathrm{~m}\right)$, and $\mathrm{H}-10\left(\delta_{\mathrm{H}} 4.38\right.$, ddd $)$ and the carbon signals of $\mathrm{C}-1\left(\delta_{\mathrm{C}} 72.6\right), \mathrm{C}-2\left(\delta_{\mathrm{C}} 41.8\right), \mathrm{C}-3\left(\delta_{\mathrm{C}} 26.7\right), \mathrm{C}-9\left(\delta_{\mathrm{C}} 52.2\right), \mathrm{C}-10\left(\delta_{\mathrm{C}} 72.9\right)$, and C-11 $\left(\delta_{\mathrm{C}} 55.0\right)$ in 3. The ${ }^{1} \mathrm{H}-{ }^{1} \mathrm{H}$ COSY correlations $(\mathrm{H}-1 / \mathrm{H}-6, \mathrm{H}-1 / \mathrm{H}-2$, and $\mathrm{H}-2 / \mathrm{H}-3)$, and $\mathrm{HMBC}$ correlation from $\mathrm{H}-17$ to $\mathrm{C}-2$ indicated that the hydroxy methine at $\mathrm{C}-2$ in $\mathbf{1}$ were replaced by a methylene in 3 (Table 1 and Table S3, and Figures S17 and S20). In addition, the ${ }^{1} \mathrm{H}-{ }^{1} \mathrm{H}$ COSY correlations $(\mathrm{H}-9 / \mathrm{H}-10, \mathrm{H}-10 / \mathrm{H}-11$, and $\mathrm{H}-11 / \mathrm{H}-12)$ and $\mathrm{HMBC}$ correlations (H-20/C-9, H-12/C-10, and H-16/C-11) demonstrated that the methylene at C-10 in $\mathbf{1}$ were replaced by a hydroxy methine in $\mathbf{3}$ (Table 1 and Table S3, and Figures S17 and S20). The HMBC correlations for the 6-5-6-6 skeleton were the same as those of $\mathbf{1}$ and $\mathbf{3}$ (Table S3 and Figure S20). The above evidence confirmed the planar structure of 3 . The study for the stereochemistry of 3 is described later (together with that of 4).

Trichodermanin $\mathrm{H}$ (4) had the same molecular formula $\mathrm{C}_{20} \mathrm{H}_{34} \mathrm{O}_{3}$ by HRFABMS $m / z 345.2415$ $[\mathrm{M}+\mathrm{Na}]^{+}$(calcd for $\mathrm{C}_{20} \mathrm{H}_{34} \mathrm{O}_{3} \mathrm{Na}$ : 345.2396) as that of $\mathbf{1}$ and $\mathbf{3}$ (Figure S28). Comparing the NMR spectra of 4 with those of 3 (Table 1, Tables S3 and S4, and Figures S22, S23 and S26), we proposed that the differences in the NMR chemical shifts at $\mathrm{H}-3\left(\delta_{\mathrm{H}} 1.88\right), \mathrm{H}-10\left(\delta_{\mathrm{H}} 1.59,1.80\right), \mathrm{H}-17\left(\delta_{\mathrm{H}} 3.60,3.95\right)$, C-2 $\left(\delta_{C} 36.9\right), C-3\left(\delta_{C} 34.0\right), C-9\left(\delta_{C} 43.5\right), C-10\left(\delta_{C} 21.6\right), C-11\left(\delta_{C} 44.1\right)$, and C-17 $\left(\delta_{C} 68.1\right)$ for 4 from those for 3 were caused by a change in the linkage position of the two hydroxy groups, i.e., 4 was a positional isomer of 3. The NMR spectral features (Table 1, Tables S1 and S4, and Figures S22, S23 and S26) resembled those of 1 , except for the proton signals for $\mathrm{H}-2\left(\delta_{\mathrm{H}} 2.74\right.$, ddd and $\delta_{\mathrm{H}} 1.64$, ddd $)$ and $\mathrm{H}-17\left(\delta_{\mathrm{H}} 3.60, \mathrm{dd}\right.$ and $\left.3.95, \mathrm{dd}\right)$ and the carbon signals of $\mathrm{C}-1\left(\delta_{\mathrm{C}} 72.1\right)$ and $\mathrm{C}-17\left(\delta_{\mathrm{C}} 68.1\right)$ in 4 . These data and the ${ }^{1} \mathrm{H}-{ }^{1} \mathrm{H}$ COSY correlation between $\mathrm{H}-3$ and $\mathrm{H}-17$ and $\mathrm{H}-9$ and $\mathrm{H}-10$ indicated the planar structure of 2 (Figure S24). This structure was supported by the HMBC correlations observed being similar to those of 1, 2, and $\mathbf{3}$ (Table S4, and Figure S27). The most remarkable structural feature of 4 was that $3-\mathrm{CH}_{3}(\mathrm{C}-17)$ in the previous trichodermanins was replaced with a hydroxy methyl group.

The relative stereochemical configurations and conformations of $\mathbf{3}$ and $\mathbf{4}$ were investigated by NOESY experiments (Tables S3 and S4, Figure 6, and Figures S18 and S25). The key NOESY correlations for ring $\mathrm{A}(\mathrm{H}-2 \alpha / \mathrm{H}-19, \mathrm{H}-1 / \mathrm{H} 20$, and $\mathrm{H}-3 / \mathrm{H}-20)$, ring $\mathrm{B}(\mathrm{H}-7 \alpha / \mathrm{H}-12, \mathrm{H}-7 \alpha / \mathrm{H}-18$, and $\mathrm{H}-12 / \mathrm{H}-18)$, and ring $\mathrm{C}(\mathrm{H}-3 / \mathrm{H}-11, \mathrm{H}-11 / \mathrm{H}-14 \beta$, and $\mathrm{H}-13 \alpha / \mathrm{H}-18)$ showed that the relative configurations and conformations in the 6-5-6-6 ring system of 3 and 4 were identical with those of the above metabolites (Tables S3 and S4, Figure 6, and Figures S18 and S25). The absolute configurations of 3 and 4 were not positively elucidated because of the small amount of material available. However, it is 
unreasonable to assume that only 3 and 4 derived from the same fungus are enantiomers of other trichodermanins. Therefore, we suggest the absolute stereostructures of $\mathbf{3}$ and $\mathbf{4}$ as shown in Figure 1 based on assumed biosynthetic relatedness. These stereostructural hypotheses will be confirmed using the modified Mosher's method [15], the quantum chemical equivalent circulating density (ECD) calculation method [17], or synthetic research in the future.

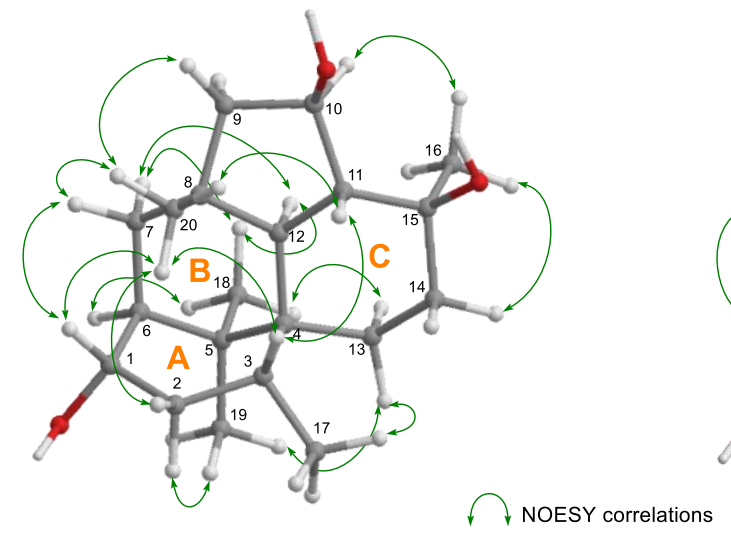

3

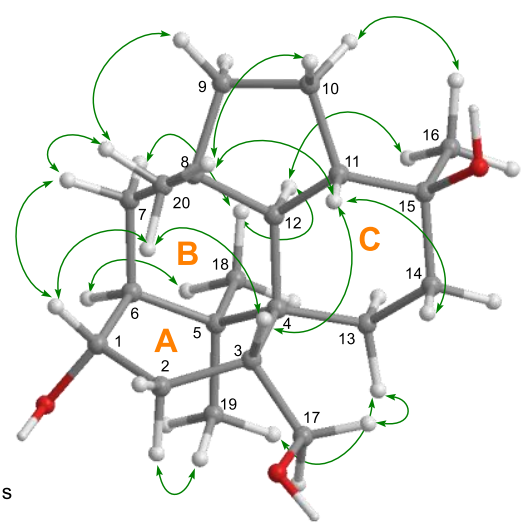

4

Figure 6. Key NOESY correlations for 3 and 4.

As a primary screen for antitumor activity, the cancer cell growth inhibitory properties of trichodermanins E-H (1-4) were examined using murine P388 leukemia, human HL-60 leukemia, and murine L1210 leukemia cell lines. The results are shown in Table 2. Both $\mathbf{1}$ and $\mathbf{2}$ exhibited modest activities against the cell lines, although they were inferior to that of 5-fluorouracil (Table 2). However, 3 and 4 did not inhibit cell growth at all (Table 2). In the study of the structure-activity relationship inferred from the activities of 1-4 and previous trichodermanins $E$ and $D$, the binding positions (C-1, C-2, C-6, C-10, and C-17) of the hydroxy groups did not contribute to the enhancement of activity. The number had some influence, i.e., the activities of diol derivatives as 2 and trichodermanins $C$ were more potent than those of the triol derivatives as 1, 3, 4, and trichodermanin D. In particular, trichodermanins $\mathrm{C}$ with a carbonyl group at C-1 showed strong activity comparable to 5-fluorouracil. We speculate that the significant cell growth inhibition of trichodermanins $C$ was caused by the change of conformation of A ring due to the carbonyl group at C-1. A comparison of cytotoxicity with normal cell and an elucidation of the detailed mechanism of activity will continue to be examined after supply of these fungal metabolites.

Table 2. Cytotoxicity of metabolites $\mathbf{1}-\mathbf{3}$ against cancer cell lines.

\begin{tabular}{cccc}
\hline \multirow{2}{*}{ Compounds } & Cell line P388 & Cell line HL-60 & Cell line L1210 \\
\cline { 2 - 4 } & $\mathrm{IC}_{\mathbf{5 0}}(\boldsymbol{\mu M})^{\boldsymbol{a}}$ & $\mathrm{IC}_{\mathbf{5 0}}(\boldsymbol{\mu \mathbf { M }})^{\boldsymbol{a}}$ & IC $_{\mathbf{5 0}}(\boldsymbol{\mu} \mathbf{M})^{\boldsymbol{a}}$ \\
\hline $\mathbf{1}$ & $52.1 \pm 1.3$ & $59.8 \pm 2.2$ & $125.2 \pm 4.3$ \\
$\mathbf{2}$ & $58.9 \pm 1.2$ & $42.9 \pm 3.0$ & $41.5 \pm 2.5$ \\
$\mathbf{3}$ & $>300$ & $>300$ & $>300$ \\
$\mathbf{4}$ & $>300$ & $85.3 \pm 2.1$ & $73.2 \pm 2.2$ \\
DMSO (control) $^{\text {5-fluorouracil }}{ }^{b}$ & $>300$ & $>300$ & $>300$ \\
\hline
\end{tabular}

${ }^{a}$ DMSO was used as vehicle. ${ }^{b}$ Positive control. 


\section{Materials and Methods}

\subsection{General Experimental Procedures}

These are the same procedures as those in recent reports [7-11]. NMR spectra were recorded on an Agilent-NMR-vnmrs (Agilent Technologies, Santa Clara, CA, USA) 600 with tetramethylsilane (TMS) as an internal reference. FABMS was recorded using a JEOL JMS-7000 mass spectrometer (JEOL, Tokyo, Japan). IR spectra were recorded on a JASCO FT/IR-680 Plus (Tokyo, Japan). Optical rotations were measured using a JASCO DIP-1000 digital polarimeter (Tokyo, Japan). Silica gel 60 (230-400 mesh, Nacalai Tesque, Inc., Kyoto, Japan) was used for column chromatography with medium pressure. Octadecyl silica (ODS) HPLC was run on a JASCO PU-1586 (Tokyo, Japan) equipped with a differential refractometer RI-1531 (Tokyo, Japan) and Cosmosil packed column 5C18-MSII ( $25 \mathrm{~cm} \times 20 \mathrm{~mm}$ i.d., Nacalai Tesque, Inc., Kyoto, Japan). Analytical thin-layer chromatography (TLC) was performed on precoated Merck aluminum sheets (DC-Alufolien Kieselgel 60 F254, 0.2 mm, Merck, Darmstadt, Germany) with the solvent system $\mathrm{CH}_{2} \mathrm{Cl}_{2} / \mathrm{MeOH}$ (19:1) (Nacalai Tesque, Inc., Kyoto, Japan), and compounds were viewed under a UV lamp (AS ONE Co., Ltd., Osaka, Japan) and sprayed with 10\% $\mathrm{H}_{2} \mathrm{SO}_{4}$ (Nacalai Tesque, Inc., Kyoto, Japan), followed by heating.

\subsection{Fungal Material}

This study is a follow-up report for this fungal strain. As shown in the previous reports [9], the fungus Trichoderma harzianum was isolated from a piece of inner tissue of the marine sponge Halichondria okadai collected at Osaka Bay, Japan, in October 2008. The fungal strain was identified by Techno Suruga Laboratory Co., Ltd. The sponge was wiped with EtOH and a cutting applied to the surface of nutrient agar layered in a Petri dish. Serial transfers of one of the resulting colonies provided a pure strain of T. harzianum.

\subsection{Culturing and Isolation of Metabolites}

The EtOAc extract $(8.6 \mathrm{~g})$ of the culture filtrate, which was obtained as described in previous reports [9-12], was chromatographed on a silica gel column with a $\mathrm{CHCl}_{3} / \mathrm{MeOH}$ gradient as the eluent to afford Fr. 1 (5\% MeOH in $\mathrm{CHCl}_{3}$ eluate, $65.6 \mathrm{mg}$ ) and $\mathrm{Fr} .2\left(5 \% \mathrm{MeOH}\right.$ in $\mathrm{CHCl}_{3}$ eluate, $119.7 \mathrm{mg}$ ). Fr. 1 was purified by ODS HPLC using $\mathrm{MeOH} / \mathrm{H}_{2} \mathrm{O}(80: 20)$ as the eluent to afford Fr. 3 (11.3 mg) and 2 ( $\left.3.7 \mathrm{mg}, t_{R} 60 \mathrm{~min}\right)$. Fr. 3 was purified by HPLC using $\mathrm{MeCN} / \mathrm{H}_{2} \mathrm{O}(40: 60)$ as the eluent to afford 1 $\left(0.93 \mathrm{mg}, t_{R} 27.5 \mathrm{~min}\right)$. Fr. 2 was purified by ODS HPLC using $\mathrm{MeOH} / \mathrm{H}_{2} \mathrm{O}(80: 20)$ as the eluent to afford Fr. 4 (9.9 mg). Fr. 4 was purified by HPLC using $\mathrm{MeCN} / \mathrm{H}_{2} \mathrm{O}(30: 70)$ as the eluent to afford 3 $\left(0.8 \mathrm{mg}, t_{R} 58 \mathrm{~min}\right)$ and $4\left(1.3 \mathrm{mg}, t_{R} 60 \mathrm{~min}\right)$

Trichodermanins E (1): pale yellow oil; $[\alpha]_{\mathrm{D}}^{22}+188.0$ ( c 0.09, MeOH); IR (neat) $v_{\max } / \mathrm{cm}^{-1}: 3383$. HRFABMS m/z $345.2397[\mathrm{M}+\mathrm{Na}]^{+}$(calcd for $\mathrm{C}_{20} \mathrm{H}_{34} \mathrm{O}_{3} \mathrm{Na}$ : 345.2396); NMR data, see Table 1 and Table S1 and the previous report [12].

Trichodermanins F (2): pale yellow oil; $[\alpha]_{\mathrm{D}}^{22}+22.4$ (c 0.24, MeOH); IR (neat) $v_{\max } / \mathrm{cm}^{-1}: 3398$. HRFABMS $m / z 289.2534[\mathrm{M}-\mathrm{Na}]^{+}$(calcd for $\mathrm{C}_{20} \mathrm{H}_{34} \mathrm{O}_{3} \mathrm{Na}$ : 289.2532). NMR data, see Table 1 and Table S2.

Trichodermanins G (3): pale yellow oil; $[\alpha]_{\mathrm{D}}^{22}+8.0\left(\right.$ c 0.08, MeOH); IR (neat) $v_{\max } / \mathrm{cm}^{-1}: 3387$. HRFABMS $m / z 345.2395[\mathrm{M}+\mathrm{Na}]^{+}$(calcd for $\mathrm{C}_{20} \mathrm{H}_{34} \mathrm{O}_{3} \mathrm{Na}$ : 345.2396). NMR data, see Table 1 and Table S3.

Trichodermanin H (4): pale yellow oil; $[\alpha]_{\mathrm{D}}^{22}+52.0(c 0.04, \mathrm{MeOH}) ; \mathrm{IR}$ (neat) $v_{\max } / \mathrm{cm}^{-1}: 3359$. FABMS $m / z$ (rel. int.): 345 ([M + Na $\left.]^{+}, 37.4 \%\right) 305$ (43.8\%), 287 (54.5\%), 115 (100\%). HRFABMS m/z $345.2415[\mathrm{M}+\mathrm{Na}]^{+}$(calcd for $\mathrm{C}_{20} \mathrm{H}_{34} \mathrm{O}_{3} \mathrm{Na}$ : 345.2396). NMR data, see Table 1 and Table S4.

\subsection{Formation of Dibenzoate of 1}

To a solution of $\mathbf{1}(1.8 \mathrm{mg}, 5.6 \mu \mathrm{mol})$ in abs. pyridine $(0.3 \mathrm{~mL}), p$-bromobenzoyl chloride $(3.0 \mathrm{mg}$, $13.6 \mu \mathrm{mol}$ ) was added, and the reaction mixture was stirred at room temperature for $15 \mathrm{~h}$. Water 
$(1.0 \mathrm{~mL})$ was added to the reaction mixture and extracted using $\mathrm{CH}_{2} \mathrm{Cl}_{2}$. The organic layer was evaporated under reduced pressure, and the residue was purified by HPLC using $100 \% \mathrm{MeOH}$ as the eluent to afford dibenzoate $1 \mathrm{a}(2.2 \mathrm{mg}, 58.8 \%)$ as a pale yellow oil.

Dibenzoate 1a: pale yellow oil; HRFABMS $m / z$ 709.1138 [M + Na ${ }^{+}$(calcd for $\mathrm{C}_{34} \mathrm{H}_{40} \mathrm{O}_{5}{ }^{79} \mathrm{Br}_{2} \mathrm{Na}$ : 709.1139). ${ }^{1} \mathrm{H}$ NMR data (TMS, $\left.\mathrm{CDCl}_{3}\right) \delta$ ppm: $1.04(3 \mathrm{H}, \mathrm{s}), 1.13,1.21(3 \mathrm{H}, \mathrm{d}), 1.22(3 \mathrm{H}, \mathrm{s}), 1.23(3 \mathrm{H}, \mathrm{s})$, $1.24(3 \mathrm{H}, \mathrm{s}), 1.26(3 \mathrm{H}, \mathrm{s}), 1.28,1.47,1.56,1.58,1.68,1.82,1.85,1.88,1.92,2.07,2.25,5.50(1 \mathrm{H}, \mathrm{d}), 5.85(1 \mathrm{H}$, dd), 7.56 (Ar. H), 7.81 (Ar. H), 7.88 (Ar. H).

\subsection{Formation of the (S)- and (R)-MTPA Esters of 2}

To a solution of $2(1.0 \mathrm{mg}, 3.3 \mu \mathrm{mol})$ in abs. pyridine $(0.3 \mathrm{~mL}),(R)-(-)-$ MTPA chloride $(3.0 \mathrm{mg}$, $15.7 \mu \mathrm{mol}$ ) was added, and the reaction mixture was stirred at room temperature for $2 \mathrm{~h}$. The reaction mixture was evaporated under reduced pressure, and the residue was purified by HPLC using $\mathrm{MeOH}-\mathrm{H}_{2} \mathrm{O}(90: 10)$ as the eluent to afford (S)-MTPA ester $\mathbf{2 a}(0.8 \mathrm{mg}, 47.2 \%)$.

$2(1.2 \mathrm{mg}, 3.9 \mu \mathrm{mol})$ and $(S)-(+)-\mathrm{MTPA}$ chloride $(3.0 \mathrm{mg}, 15.7 \mu \mathrm{mol})$ were treated with the same procedure to afford $(R)$-MTPA ester $\mathbf{2 b}(1.5 \mathrm{mg}, 73.7 \%)$.

MTPA ester 2a: pale yellow oil; HRFABMS $m / z 545.2860[\mathrm{M}+\mathrm{Na}]^{+}$(calcd for $\mathrm{C}_{30} \mathrm{H}_{41} \mathrm{~F}_{3} \mathrm{O}_{4} \mathrm{Na}$ : 545.2855) (Figure S32). ${ }^{1} \mathrm{H}$ NMR data and spectrum including 2D NMR spectra are listed in Table S5, and Figures S29-S31 of Supplementary Materials.

MTPA ester 2b: pale yellow oil; HRFABMS m/z $545.2849[\mathrm{M}+\mathrm{Na}]^{+}$(calcd for $\mathrm{C}_{30} \mathrm{H}_{41} \mathrm{~F}_{3} \mathrm{O}_{4} \mathrm{Na}$ : 545.2855) (Figure S36). ${ }^{1} \mathrm{H}$ NMR data and spectrum including 2D NMR spectra are listed in Table S5, and Figures S33-S35 of Supplementary Materials.

\subsection{Assay for Cytotoxicity}

Cytotoxic activities of $\mathbf{1 - 4}$ were examined by the same procedure to date [5-12,18], i.e., the 3-(4,5-dimethyl-2-thiazolyl)-2,5-diphenyl-2H-tetrazolium bromide (MTT) method. P388, HL-60, and L1210 cells were cultured in RPMI 1640 Medium (10\% fetal calf serum) at $37{ }^{\circ} \mathrm{C}$ in $5 \% \mathrm{CO}_{2}$. The test materials were dissolved in dimethyl sulfoxide (DMSO) to give a concentration of $10 \mathrm{mM}$, and the solution was diluted with the Essential Medium to yield concentrations of 200, 20, and $2 \mu \mathrm{M}$, respectively. Each solution was combined with each cell suspension $\left(1 \times 10^{5} \mathrm{cells} / \mathrm{mL}\right)$ in the medium, respectively. After incubating at $37^{\circ} \mathrm{C}$ for $72 \mathrm{~h}$ in $5 \% \mathrm{CO}_{2}$, grown cells were labeled with $5 \mathrm{mg} / \mathrm{mL}$ MTT in phosphate-buffered saline (PBS), and the absorbance of formazan dissolved in $20 \%$ sodium dodecyl sulfate (SDS) in $0.1 \mathrm{~N} \mathrm{HCl}$ was measured at $540 \mathrm{~nm}$ with a microplate reader (MTP-310, CORONA electric). Each absorbance value was expressed as percentage relative to that of the control cell suspension that was prepared without the test substance using the same procedure as that described above. All assays were performed three times, semilogarithmic plots were constructed from the averaged data, and the effective dose of the substance required to inhibit cell growth by $50 \%\left(\mathrm{IC}_{50}\right)$ was determined.

\subsection{The Origin of the Cell Lines}

P388 cell line was obtained from Dr. Numata. HL-60 cell line was obtained from Dr. Kawai. L1210 cell line was from Dr. Endo.

\section{Conclusions}

In this study, three new terpenes with a rare fused 6-5-6-6 ring system, namely, trichodermanins E-H (1-4), were isolated from the fungus T. harzianum separated from the marine sponge H. okadai. Spectral analyses and chemical transformations were utilized to elucidate the absolute stereostructures of $\mathbf{1}$ and 2. The relative stereostructures of $\mathbf{3}$ and $\mathbf{4}$ were assumed to be those of the same class of metabolites. Therefore, we deduced that their absolute configurations were also the same as those of other trichodermanins. In cytotoxic assays performed using three cancer cell lines, $\mathbf{1}$ and $\mathbf{2}$ exhibited moderate activity against the cell lines, although they were inferior to that of 5-fluorouracil. 
Supplementary Materials: The following are available online at http://www.mdpi.com/1660-3397/17/8/480/s1, Table S1: Spectral data including 2D NMR data for 1, Table S2: Spectral data including 2D NMR data for 2, Table S3: Spectral data including 2D NMR data for 3, Table S4: Spectral data including 2D NMR data for 4, Table S5: Spectral data for $\mathbf{2 a}$ and $\mathbf{2 b}$, Figure S1: ${ }^{1} \mathrm{H}$ NMR spectrum of $\mathbf{1}$ in $\mathrm{CDCl}_{3}$, Figure S2: ${ }^{13} \mathrm{C}$ NMR spectrum of 1 in $\mathrm{CDCl}_{3}$, Figure S3: ${ }^{1} \mathrm{H}-{ }^{1} \mathrm{H}$ COSY of 1, Figure S4: NOESY of 1, Figure S5: HMQC of 1, Figure S6: HMBC of 1, Figure S7: FABMS of 1, Figure S8: ${ }^{1} \mathrm{H}$ NMR spectrum of 2 in $\mathrm{CDCl}_{3}$, Figure S9: ${ }^{13} \mathrm{C}$ NMR spectrum of 2 in $\mathrm{CDCl}_{3}$, Figure S10: ${ }^{1} \mathrm{H}-{ }^{1} \mathrm{H}$ COSY of 2, Figure S11: NOESY of 2, Figure S12: HMQC of 2, Figure S13: HMBC of 2, Figure S14: FABMS of 2, Figure S15: ${ }^{1} \mathrm{H}$ NMR spectrum of 3 in $\mathrm{CDCl}_{3}$, Figure S16: ${ }^{13} \mathrm{C}$ NMR spectrum of 3 in $\mathrm{CDCl}_{3}$, Figure S17: ${ }^{1} \mathrm{H}-{ }^{1} \mathrm{H}$ COSY of 3, Figure S18: NOESY of 3, Figure S19: HMQC of 3, Figure S20: HMBC of 3, Figure S21: FABMS of 3, Figure S22: ${ }^{1} \mathrm{H}$ NMR spectrum of 4 in $\mathrm{CDCl}_{3}$, Figure S23: ${ }^{13} \mathrm{C}$ NMR spectrum of 4 in $\mathrm{CDCl}_{3}$, Figure S24: ${ }^{1} \mathrm{H}-{ }^{1} \mathrm{H}$ COSY of 4, Figure S25: NOESY of 4, Figure S26: HMQC of 4, Figure S27: HMBC of 4, Figure S28: FABMS of 4, Figure S29: ${ }^{1} \mathrm{H}$ NMR spectrum of $2 \mathbf{a}$ in $\mathrm{CDCl}_{3}$, Figure S30: ${ }^{1} \mathrm{H}-{ }^{1} \mathrm{H}$ COSY of $2 \mathbf{a}$,

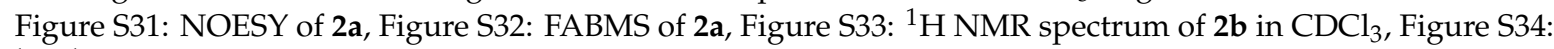
${ }^{1} \mathrm{H}-{ }^{1} \mathrm{H}$ COSY of $\mathbf{2} \mathbf{b}$, Figure S35: NOESY of $\mathbf{2} \mathbf{b}$, Figure S36: FABMS of $\mathbf{2} \mathbf{b}$.

Author Contributions: T.Y., A.F., and T.K conceived and designed the experiments; T.Y. and A.F. performed the experiments; T.Y. analyzed the data; and T.Y. wrote the paper.

Funding: This research received no external funding.

Acknowledgments: We thank Endo (Kanazawa University) for supply of the cancer cells. We are grateful to M. Fujitake and K. Minoura of this university for MS and NMR measurements, respectively.

Conflicts of Interest: The authors declare no conflict of interest.

\section{References}

1. Nicoletti, R.; Vinale, F. Bioactive Compounds from Marine-Derived Aspergillus, Penicillium, Talaromyces and Trichoderma Species. Mar. Drugs 2018, 16, 408. [CrossRef] [PubMed]

2. Imhoff, J. Natural Products from Marine Fungi-Still an Underrepresented Resource. Mar. Drugs 2016, 14, 19. [CrossRef] [PubMed]

3. Blunt, J.W.; Copp, B.R.; Keyzers, R.A.; Munro, M.H.G.; Prinsep, M.R. Marine natural products. Nat. Prod. Rep. 2017, 34, 235-294. [CrossRef] [PubMed]

4. $\quad$ Blunt, J.W.; Carroll, A.R.; Copp, B.R.; Davis, R.A.; Keyzers, R.A.; Prinsep, M.R. Marine natural 369 products. Nat. Prod. Rep. 2018, 35, 8-53. [CrossRef] [PubMed]

5. Yamada, T.; Iritani, M.; Ohishi, H.; Tanaka, K.; Minoura, K.; Doi, M.; Numata, A. Pericosines, antitumour metabolites from the sea hare-derived fungus Periconia byssoides. Structures and biological activities. Org. Biomol. Chem. 2007, 5, 3979-3986. [CrossRef] [PubMed]

6. Yamada, T.; Kitada, H.; Kajimoto, T.; Numata, A.; Tanaka, R. The relationship between the CD Cotton effect and the absolute configuration of FD-838 and its seven stereoisomers. J. Org. Chem. 2010, 75, 4146-4153. [CrossRef] [PubMed]

7. Yamada, T.; Kikuchi, T.; Tanaka, R. Altercrasin A, a novel decalin derivative with spirotetramic acid, produced by a sea urchin-derived Alternaria sp. Tetrahedron Lett. 2015, 56, 1229-1232. [CrossRef]

8. Yamada, T.; Tanaka, A.; Nehira, T.; Nishii, T.; Kikuchi, T. Altercrasins A-E, decalin derivatives, from a sea-urchin-derived Alternaria sp.: Isolation and structural analysis including stereochemistry. Mar. Drugs 2019, 17, 218. [CrossRef] [PubMed]

9. Yamada, T.; Mizutani, Y.; Umebayashi, Y.; Inno, N.; Kawashima, M.; Kikuchi, T.; Tanaka, R. A novel ketoaldehyde decalin derivative, produced by a marine sponge-derived Trichoderma harzianum. Tetrahedron Lett. 2014, 55, 662-664. [CrossRef]

10. Yamada, T.; Umebayashi, Y.; Kawashima, M.; Sugiura, Y.; Kikuchi, T.; Tanaka, R. Determination of the chemical structures of tandyukisins B-D, isolated from a marine sponge-derived fungus. Mar. Drugs 2015, 13, 3231-3240. [CrossRef] [PubMed]

11. Suzue, M.; Kikuchi, T.; Tanaka, R.; Yamada, T. Tandyukisins E and F, novel cytotoxic decalin derivatives isolated from a marine sponge-derived fungus. Tetrahedron Lett. 2016, 57, 5070-5073. [CrossRef]

12. Yamada, T.; Suzue, M.; Arai, T.; Kikuchi, T.; Tanaka, R. Trichodermanins C-E, new diterpenes with a fused 6-5-6-6 ring system produced by a marine sponge-derived fungus. Mar. Drugs 2017, 15, 169. [CrossRef] [PubMed] 
13. Sun, P.X.; Zheng, C.J.; Li, W.C.; Huang, F.; Qin, L.P. Trichodermanin A, a novel diterpenoid from endophytic fungus culture. J. Nat. Med. 2011, 65, 381-384. [CrossRef] [PubMed]

14. Yamamoto, T.; Izumi, N.; Ui, H.; Sueki, A.; Masuma, R.; Nonaka, K.; Hirose, T.; Sunazuka, T.; Nagai, T.; Yamada, H.; et al. Wickerols A and B: Novel anti-influenza virus diterpenes produced by Trichoderma atroviride FKI-3849. Tetrahedron 2012, 68, 9267-9271. [CrossRef]

15. Ohtani, I.; Kusumi, T.; Kashman, Y.; Kakisawa, H. High-field FT NMR application of Mosher's method. The absolute configurations of marine terpenoids. J. Am. Chem. Soc. 1991, 113, 4092-4096. [CrossRef]

16. Harada, N.; Nakanishi, K. Circular Dichroic Spectroscopy-Exciton Coupling in Organic Stereochemistry; University Science Books: Sausalito, CA, USA, 1983.

17. Sun, Z.H.; Gu, J.; Ye, W.; Wen, L.X.; Lin, Q.B.; Li, S.N.; Che, Y.C.; Li, H.H.; Zhang, W.M. Geospallins A-C: New thiodiketopiperazines with inhibitory activity against angiotensin-converting enzyme from a deep-Sea-derived Fungus Geosmithia pallida FS140. Mar. Drugs 2018, 16, 464. [CrossRef] [PubMed]

18. Miki, I.; Ishihara, N.; Ohtoshi, M.; Kase, H. Simple colorimetric cell-cell adhesion assay using MTT-stained leukemia cells. J. Immiunol. Methods 1993, 164, 155-261. [CrossRef]

(C) 2019 by the authors. Licensee MDPI, Basel, Switzerland. This article is an open access article distributed under the terms and conditions of the Creative Commons Attribution (CC BY) license (http://creativecommons.org/licenses/by/4.0/). 